\title{
The Automated System of Unified Templates as an Element of Trainability of Microprocessor Relay Protection Devices
}

\section{Viktor Nikolaevich Sizykh1, Aleksey Vasilyevich Daneev1, Maksim Viktorovich Vostrikov², Konstantin Vladimirovich Menaker ${ }^{2}$}

${ }^{1}$ Irkutsk State Transport University, Irkutsk, Russia

${ }^{2}$ The Transbaikal Institute of Railway Transport, Chita, Russia

Email: sizykh_vn@mail.ru,daneev@mail.ru,vostrikov_m@zab.megalink.ru,menkot@mail.ru

How to cite this paper: Sizykh, V.N., Daneev, A.V., Vostrikov, M.V. and Menaker, K.V. (2021) The Automated System of Unified Templates as an Element of Trainability of Microprocessor Relay Protection Devices. Journal of Applied Mathematics and Physics, 9, 3045-3057. https://doi.org/10.4236/jamp.2021.912197

Received: October 21, 2021

Accepted: December 12, 2021

Published: December 15, 2021

Copyright $\odot 2021$ by author(s) and Scientific Research Publishing Inc. This work is licensed under the Creative Commons Attribution International License (CC BY 4.0).

http://creativecommons.org/licenses/by/4.0/

\begin{abstract}
The article discusses the possibility of further modernization of the standard microprocessor relay protection of AC overhead system feeders DPA-27.5-TNF, which is operated on the Trans-Baikal Railway by creating an additional automated system of unified templates necessary for the occurrence of "trainability" elements. The templates will be formed via a separate dedicated channel for transmission, processing and storage of the necessary information, not related to the operation of the terminal, with its subsequent visualization at the workplace of the duty personnel of traction substations, together with information from the "GID" software received via another dedicated wired channel. With the help of such a base of unified preset templates, in the future, it will be possible not only to identify the specific causes of each emergency shutdown but also to reduce their number by dynamically adjusting the existing presets of the standard operation algorithm.
\end{abstract}

\section{Keywords}

Automated System, Microprocessor, Relay Protection Devices, Feeder, Traction Substation

\section{Introduction}

Earlier in their articles [1] the authors already considered the features of the operation of microprocessor relay protection DPA-27.5-TNF on the Trans-Baikal railway and proposed options for modernization and automation to increase the selectivity of its operation [2]. So, the previous work of this team of authors considered an alternative option for possible visualization, retrieval and storage of 
current and voltage oscillograms in online mode from modernized current and voltage modules (DCM) using an electronic USB oscilloscope HANTEK 6074 BC. It is also proposed to use data from the automated system for maintaining and analyzing the train sheet "GID" of the Ural-VNIIZhT [3], received by the duty personnel of traction substations via a dedicated wired channel. All the information obtained after analysis and the necessary transformations would be used to subsequently form a base of dynamic unified templates of presets of microprocessor relay protection.

In works with similar problems [4]-[11] foreign authors propose adaptive systems of neuro-fuzzy inference to classify faults in transmission lines and remote relay protection of the transmission line, as well as new approaches to protection transmission lines using wavelet transform and neural networks, etc. However, for the most part, such technical solutions are used in the design of new microprocessor protection systems for general industrial three-phase cable or overhead power lines and cannot be used in our case with a single-phase load (railway overhead system) and a non-standard voltage level $\mathrm{U}=27.5 \mathrm{kV}$. Separately, I would like to note interesting from the point of view of similarity problems of the article [12] [13].

The objective of this study is not to develop new approaches, methods and designs of microprocessor relay protection, but to modernize and automate the terminals that are already in operation at the moment with a minimum level of interference both in their instrumental base and in the standard algorithm of their operation.

The DPA-27.5-TNF device is made in the form of two blocks-a protection and automation unit (PAU) and a control unit (CU). In turn, the PAU, according to the principle of "cassette" formation, contains the following modules, connected one after another (Figure 1):

- Modules of current (MCS) and voltage (MVS) sensors;

- Measurement and protection controller module (MPCM);

- Automation controller module (ACM);

- Input board (IB 1);

- Output board for discrete signals (OB 2);

- Power module (PM).

Modules of current sensor (MCS) and voltage sensor module (MVS) consist of intermediate transformers and precision amplifiers. They are needed to provide galvanic isolation and pre-scaling of incoming input signals.

In the measurement and protection controller module (MPCM), analog-todigital conversion and processing of signals from previous modules take place, as well as the further transfer of these data to the automation controller module (ACM), where, after processing by the protection algorithms of the corresponding stages, a decision is made to change or save the current state of the switching devices.

The automation controller module (ACM) is the central module of DPA-27.5TNF, which includes built-in: 


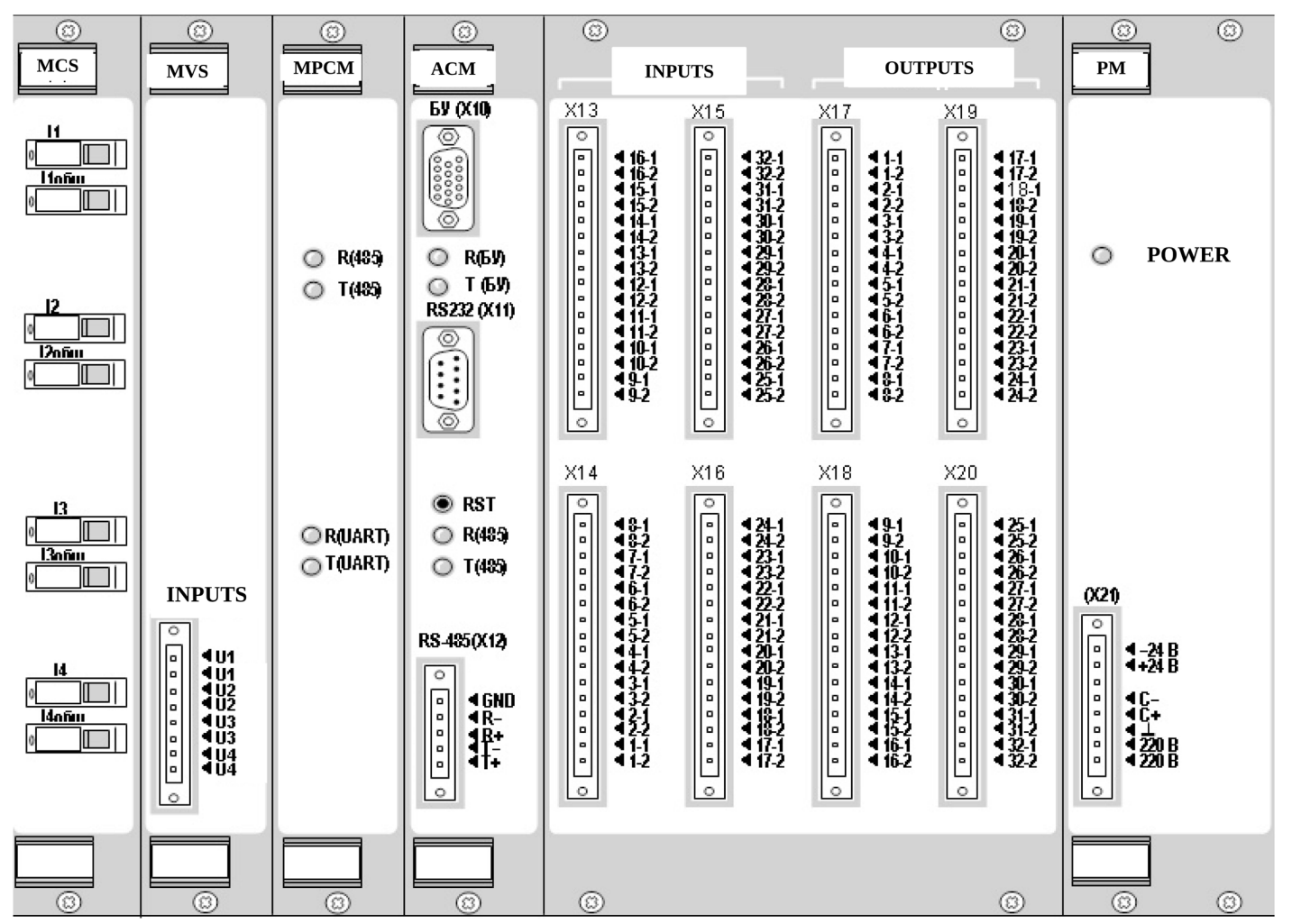

Figure 1. Appearance and location of modules in PAU DPA-27.5-TNF.

- Program memory;

- Random access memory;

- Electrically reprogrammable read-only memory (ERROM).

The input board (IB 1) contains 16 universal input cells that convert the input signals of AC or DC voltage of $220 \mathrm{~V}$ (or $110 \mathrm{~V}$ ) into logic levels of microcircuits.

The output board (OB 2) contains 15 electromagnetic relays and a transistor switch with optoelectronic insulation. Small-sized relays provide the required galvanic isolation and load capacity. Transistor switches are used in circuits with the breaker of longitudinal coupling to increase the speed of protection operating without time delay.

The power module $(\mathrm{PM})$ converts the primary supply voltage (DC, AC or rectified) into three secondary DC voltages required for the operation of the PAU unit: $+5 \mathrm{~V}$ and $\pm 15 \mathrm{~V}[13]$.

All decisions on the control of the output relays are carried out in accordance with standard protection algorithms based on the processing and comparison of the values of electrical parameters received from the MPCM to the ACM (taking into account the values of the program presets). In DPA-27.5-TNF, only one software detuning of the second and third stages from the load currents in the traction network of the power supply system is provided: exceeding the value of the corresponding preset by the value of the harmonic distortion factor $\mathrm{F}_{\mathrm{H}}$.

Thus, in modern microprocessor-based relay protection of overhead power 
line feeders, there is only a limited (unchanged) set of presets, which does not make it possible to clearly distinguish between pre-emergency and emergency modes of operation of the traction power supply system; moments of starting and transient currents flowing in the traction network when handling trains of increased weight, double trains along with a complex track profile, changing the operating modes of traction motors of electric locomotives, etc., therefore, the number of its shutdowns due to unknown reasons increases (Figure 2).

Further, a method for further modernization and automation of existing microprocessor relay protection terminals will be considered and proposed by creating an automated system for generating and storing unified preset templates and its potential integration into a standard operating algorithm to obtain "trainability" elements.

\section{Materials and Methods}

The object of research is the already partially modernized and automated protection and automation unit (PAU) of the digital protection and automation device of the $27.5 \mathrm{kV}$ traction network feeder (DPA-27.5-TNF).

The subject of the research is a standard algorithm of the operation of a digital protection device and automation of a $27.5 \mathrm{kV}$ overhead systems feeder (DPA-27.5-TNF), which is proposed to be improved through the use of an analog-to-digital converter (ADC) - an electronic USB oscilloscope, an additional (auxiliary) microcontroller (AM) and dedicated wired communication channels according to the scheme "ADC unit-AM unit-software 'GID'—the workplace of the traction substation duty personnel".

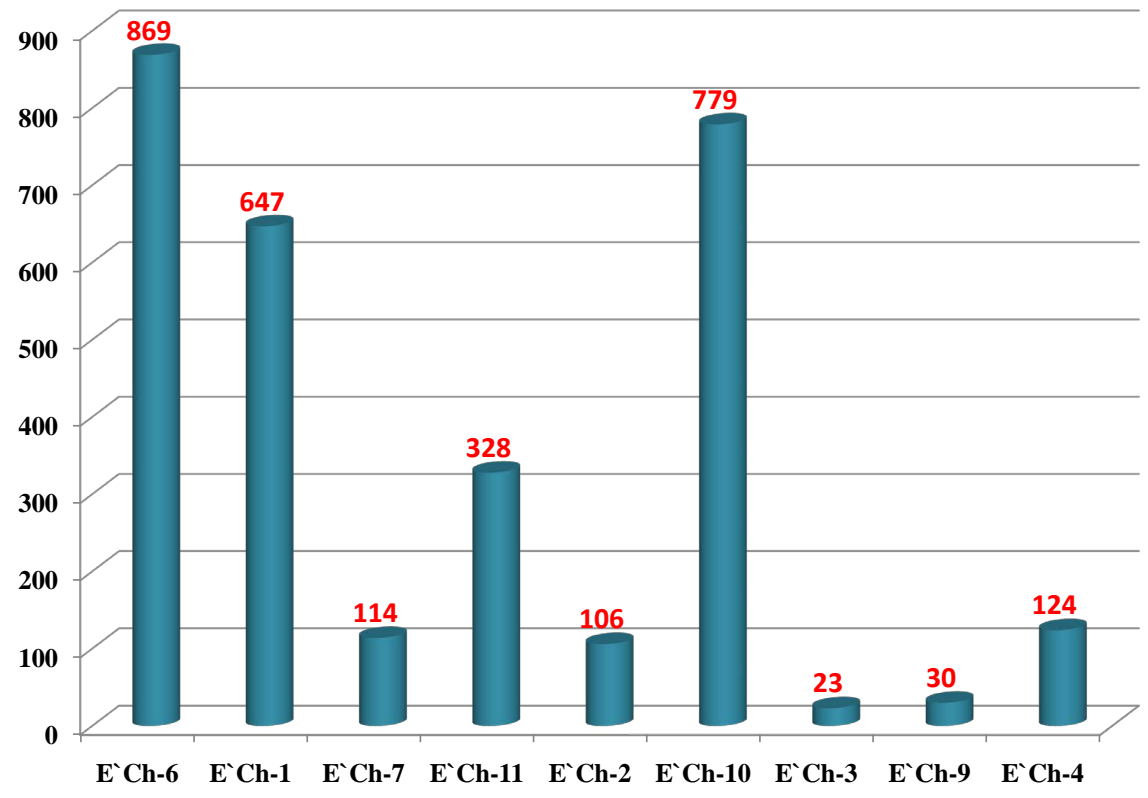

Figure 2. Distribution of the total number of shutdowns due to unknown reasons (for the period 2015-2017) of relay protection devices for power sections of the Trans-Baikal Railway. 
The study was carried out using the conversion of instantaneous values of input signals into digital values, a method of fast Fourier transform, a method of analytical representation of digitized signals using spline interpolation (first, second and third degree with various options for gluing together functions at their conjugation points), methods of adaptation and joint storage of the received data from the auxiliary microprocessor and with the specialized software "GID" (train sheet) at the workplace of the traction substation duty personnel in the form of a base of unified preset templates.

\section{Setting up the Experiment}

The section of the Sedlovoy-Buryatskaya-Mogoytui railway was chosen as an experimental one; measurements were made at the Buryatskaya traction substation (TS) (Figure 3).

The switchgear $2 \times 25 \mathrm{kV}$ at the Buryatskaya TS is a system consisting of two modules of outdoor switchgear (OS), including the cells in which the measuring

Workplace for the duty personnel of the traction substation

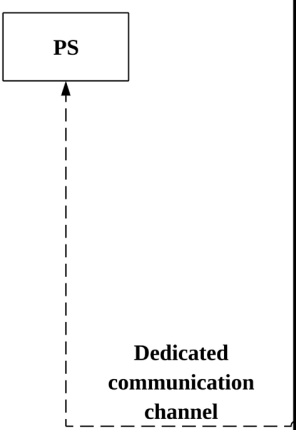

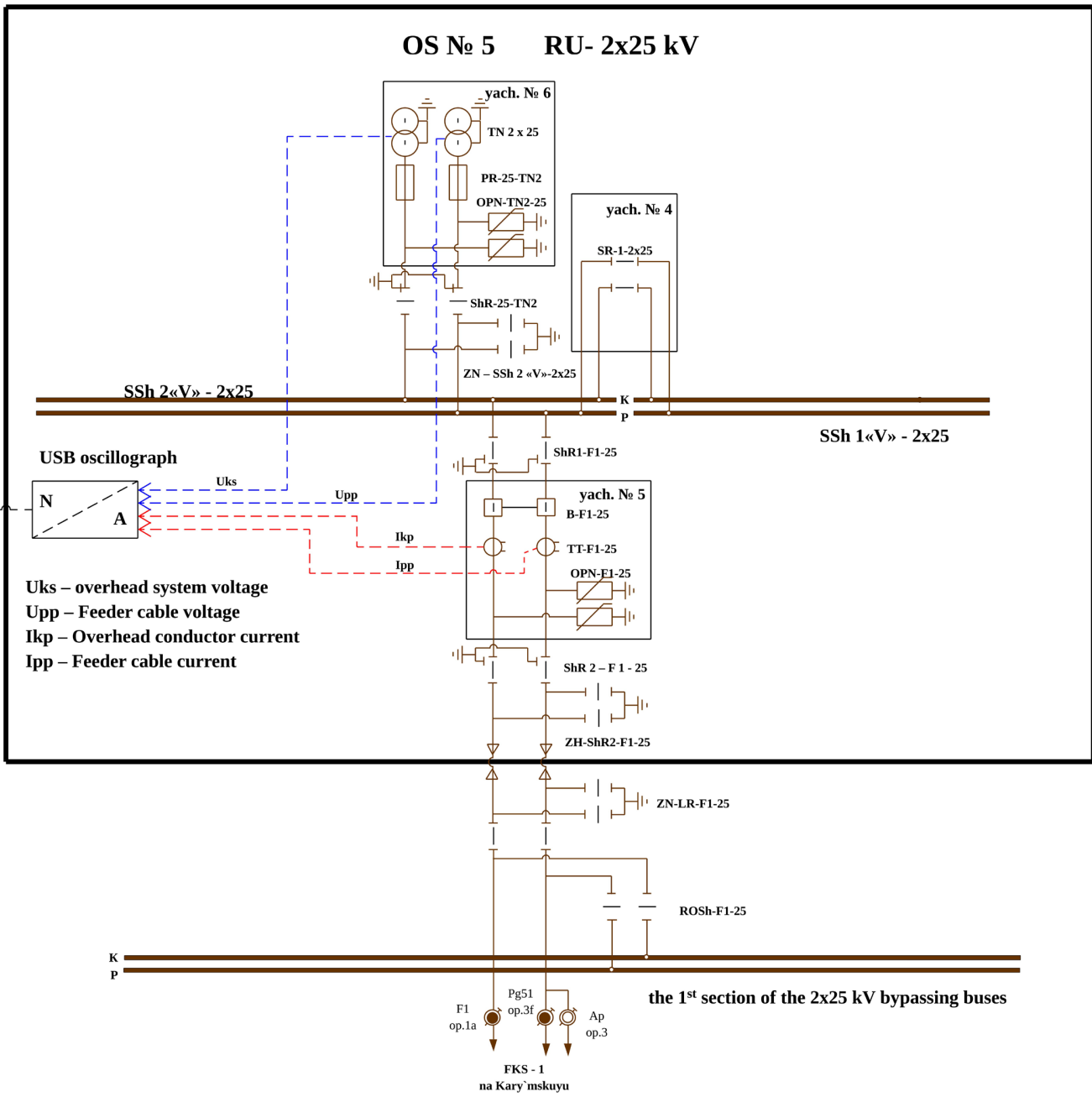

Figure 3. Fragment of the Buryatskaya TS single-line diagram showing the place of connection of the digital USB oscilloscope channels and the principle of organizing the measurements. 
current and voltage transformers are located (Figure 3, cells No. 5 and No. 6) providing galvanic isolation and preliminary scaling of input signals taken from their secondary windings, and precision amplifiers are used to accurately scale signals and match the impedances of intermediate transformers and analog-todigital converter (MCS and MVS in the relay protection terminal). Further (by means of the MPCM ADC), the instantaneous values of the input signals are converted into their digital values. Conversion data is valid for sampling rates up to $2000 \mathrm{~Hz}$. Further, the obtained digital signals of current and voltage, for the purpose of additional filtering and detailed analysis of the harmonic components in the microprocessor, pass through the operation of the fast Fourier transform. After that, the integral parameters of the monitored signals and their harmonics (amplitude, effective values, etc.) are calculated from the samples.

In modern microprocessor-based relay protection devices, an analytical representation in the form of a continuous function of current and voltage time (oscillograms) is recorded only for visualizing information at the time of its emergency activation of relay protection devices (Figure 4) [14].

When organizing the collection of the necessary information in the form of oscillograms of current and voltage in the online mode (according to the diagram shown in Figure 3), they will be broadcast and recorded on the PC of the workplace of the duty personnel of the traction substation. However, this method also has significant drawbacks - it requires a large amount of memory of the PC recorder, and, consequently, a large period of time to search and view the necessary fragment of oscillograms characterizing the pre-emergency or emergency operation of the traction power supply system [15].

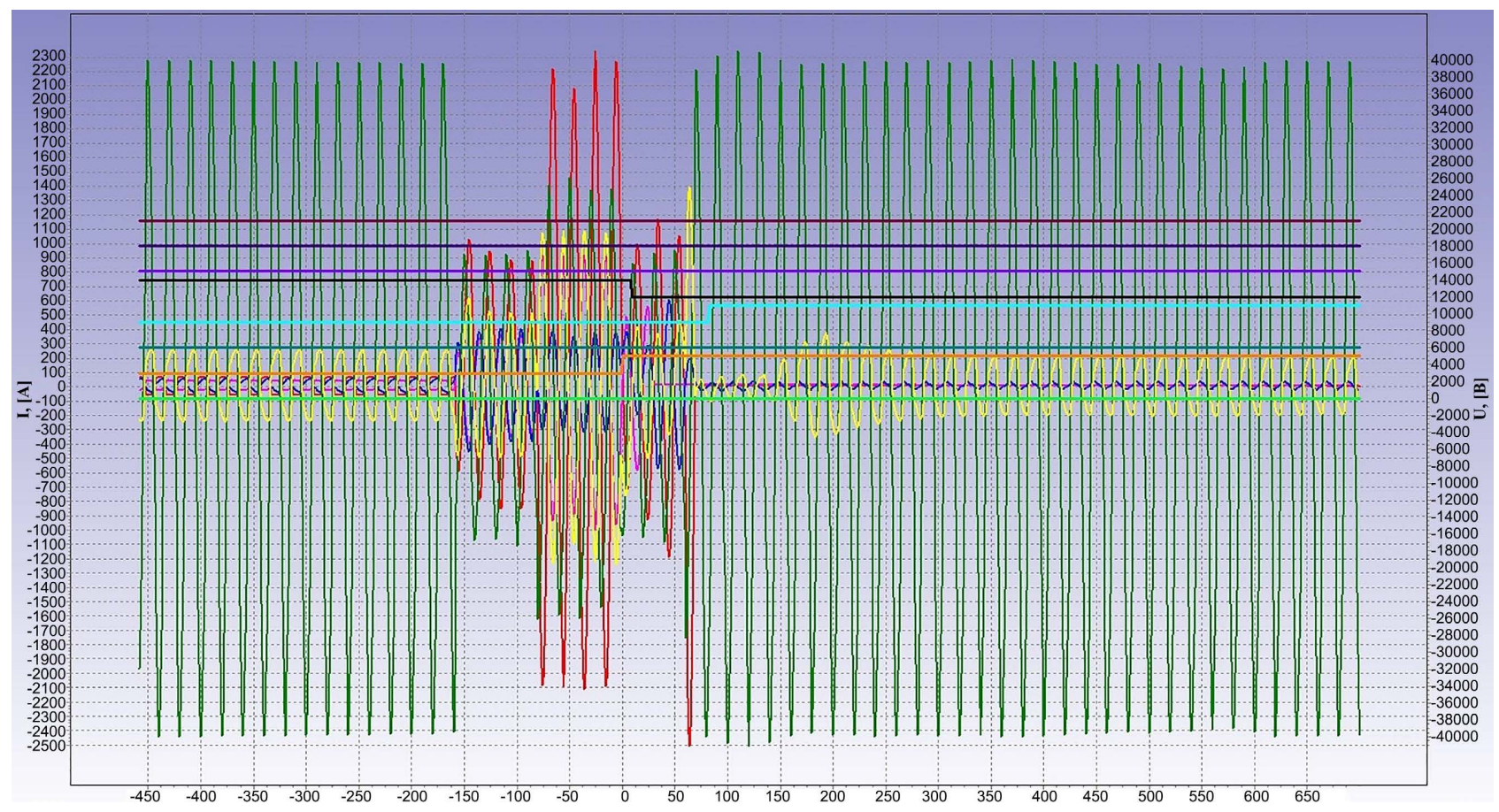

Figure 4. An example of an oscillogram of an emergency actuation of a microprocessor relay protection DPA-27.5-TNF, located at the sectioning post of Khadabulak dated April 15, 2019. 
To potentially reduce the level of upcoming information load, structuredness and optimize the information received and stored on a PC, a review and analysis of the available methods of analytical presentation and further storage of digitized signals was carried out, the most promising and advanced of which turned out to be: linear interpolation, interpolation by Lagrange and Newton polynomials, and spline interpolation [16].

After performing several calculations and carrying out their extended analysis, the team of authors became convinced of the low efficiency and expediency of using the Lagrange and Newton polynomials, based on the significant complexity of their calculations and the resulting large enough errors in the approximation of functions at intermediate points.

The choice was made in favor of spline interpolation, which allows using both first and second degree splines and cubic splines (third degree) with the possibility of variations of possible gluing options: approximation to a straight line, a parabola, and a cubic function at their conjugation points [17].

As you can see, the method of spline interpolation with the approximation of the gluing sections to a straight line (Akima's method) allows obtaining the best results (Figure 5(a)), while the method of approaching a parabola and a cubic function, especially in the presence of starting and transient currents (Figure 5(b) and Figure 5(c)) shows the worst result.

Since the relay protection terminals are physically located in $2 \times 25 \mathrm{kV}$ OS, which is located in the open part of the territory of the traction substation, in order to ensure mobility of maintenance and operation, compliance with the temperature regimes of the proposed automated system, it was decided to use

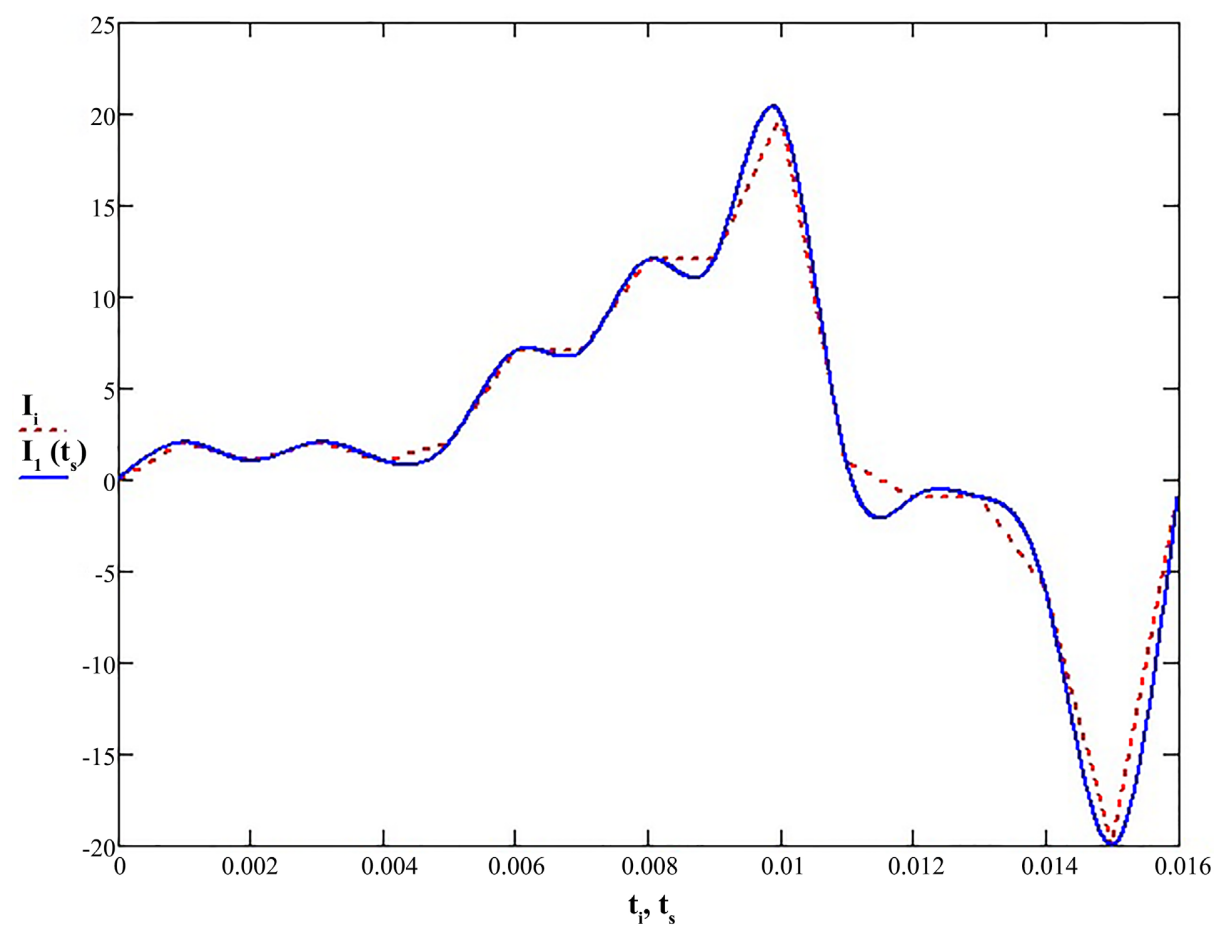

(a) 


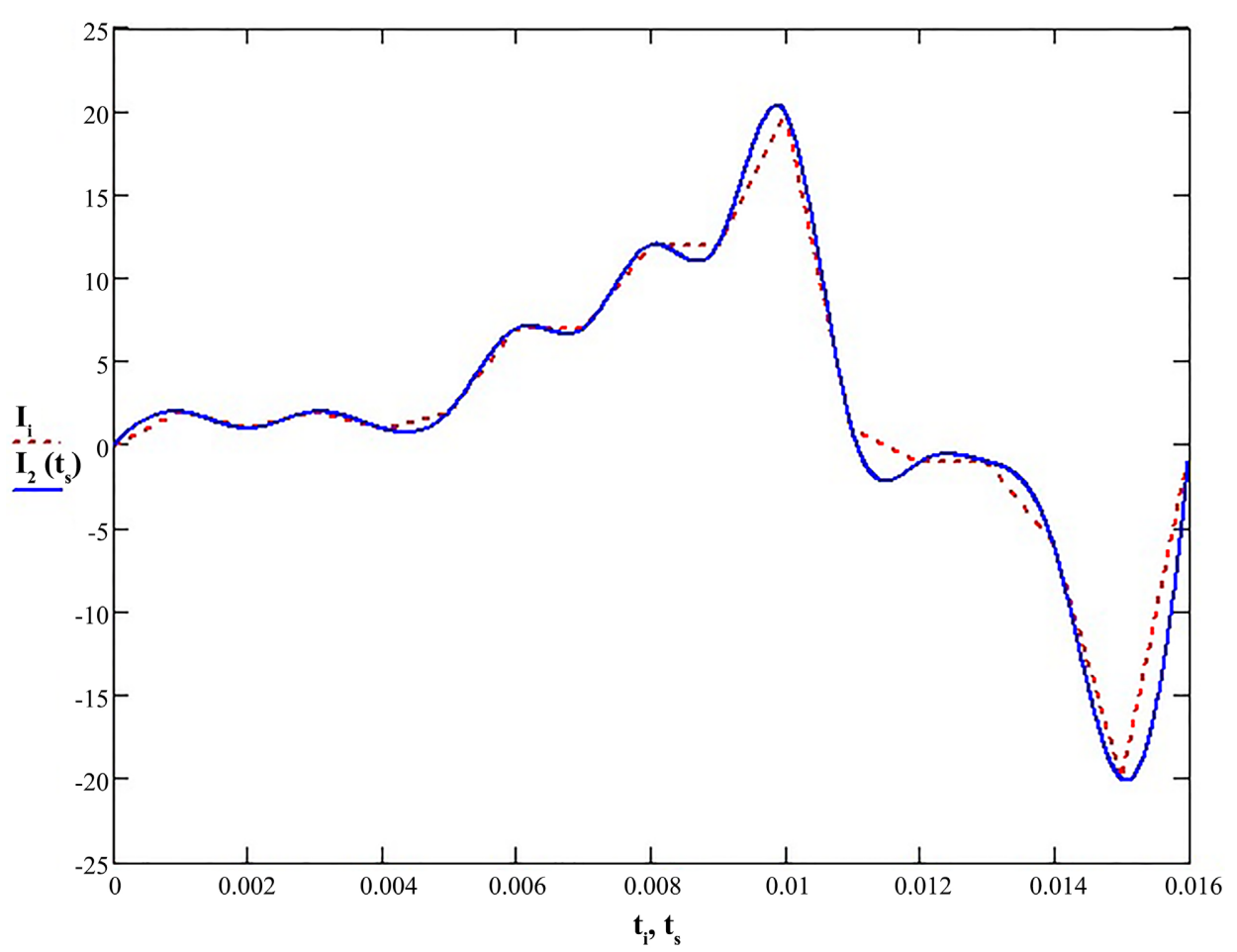

(b)

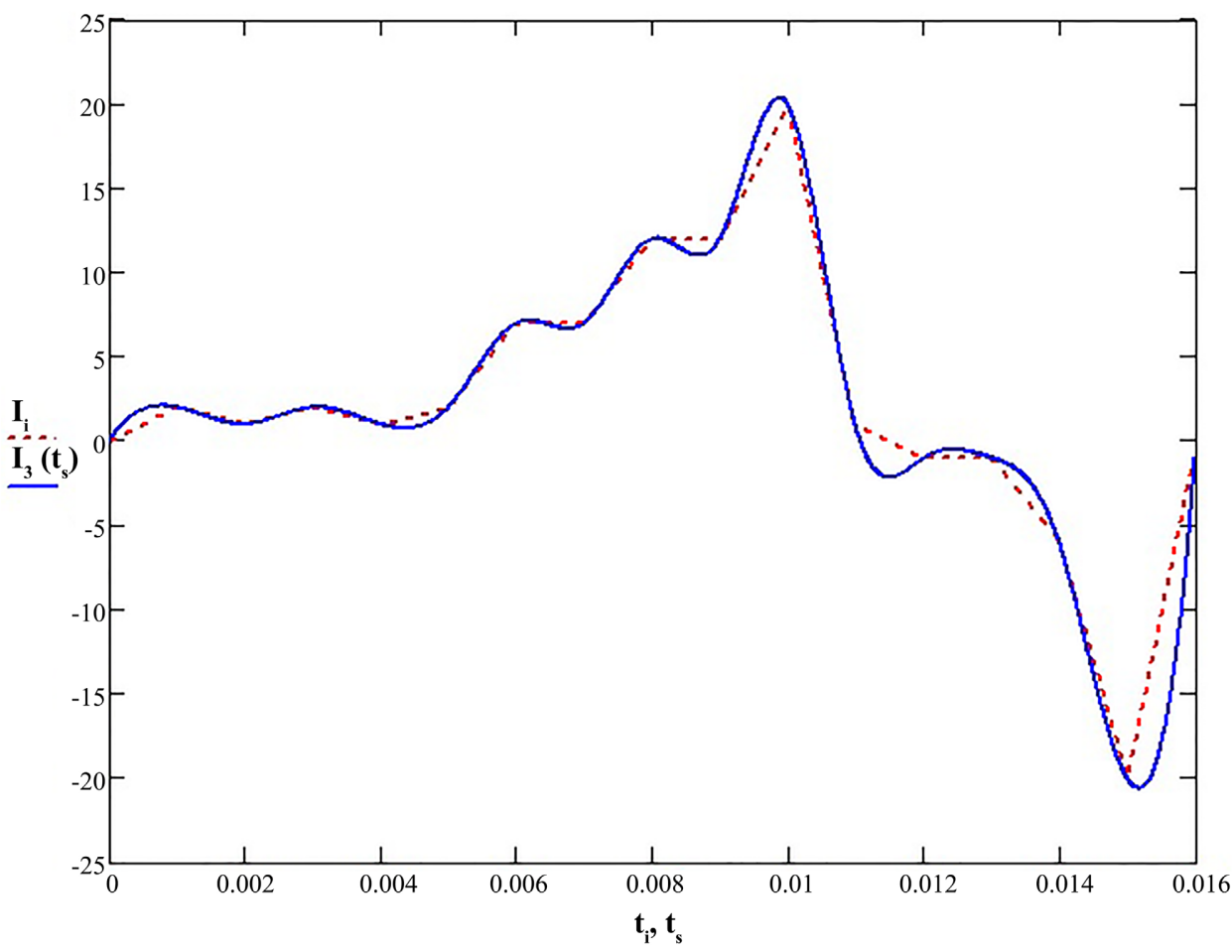

(c)

Figure 5. Fragment of the oscillogram of the original current function taken in on-line mode, combined with the function obtained in the form of cubic spline interpolation with the approximation: (a) to a straight line at the boundary points (standard deviation $\sigma=1.015$ ), (b) approaching a parabola at the boundary points (standard deviation $\sigma=1.255$ ), (c) approaching the third degree function at the boundary points (standard deviation $\sigma=1.552$ ). 
the previously upgraded relay protection terminal DPA-27.5-TNF, where (on a separate removable circuit board) there are already integrated devices for filtering and extracting the first harmonic based on the phase-lock loop and a circuit for its power supply, as well as an auxiliary microcontroller [18].

\section{Experimental Results}

The result of the experiment will be the proposed methodology and structural diagram of an automated system for organizing, collecting, processing, comparing and storing parameters necessary for the formation of unified templates typical for a particular train situation in order to potentially reduce the number of emergency actuations of relay protection devices, which is already partially integrated into the structure of a modernized and automated standard terminal for microprocessor relay protection of AC traction network feeders of the DPA27.5-TNF type (Figure 6). Let us consider in more detail the operation of the proposed automated and modernized microprocessor relay protection device.

As can be seen from the diagram itself, all the proposed automated systems are integrated into the operating relay protection terminal even at the stage of connecting electrical circuits to it from the secondary windings of the measuring current and voltage transformers (up to MCS and MVS of the PAU terminal), and, therefore, cannot influence its regular mode of operation.

Through the existing channel of the "GID" software on the PC of the duty personnel of the traction substation, the first part of information about the current train situation will be received, processed and stored in on-line mode, which is necessary to form a unified database of templates (pink lines). The second part of the information necessary for the formation of this kind of base will come online from an electronic USB oscilloscope to an auxiliary microcontroller, where, after appropriate transformations, it will also be transmitted to a PC in the form of splines (red lines). In order to simplify the process of searching and identifying the necessary fragments of pre-emergency and emergency oscillograms (the third part of the information) taken by an electronic USB oscilloscope, as well as their subsequent imposition on the emergency oscillogram recorded by the relay protection terminal, phase-lock loop (blue lines) will be used. Phase-lock loop circuits as part of the filtering devices and separating the first harmonic of current and voltage [19] make it possible to generate reference synchronization pulses when the corresponding monitored signals pass through zero marks (an auxiliary microcontroller puts a kind of "notch" in the required place of the oscillogram, thereby already classifying it as a pre-emergency or emergency in the proposed automation systems).

Thus, from these three components of information received from the corresponding automated systems operating in on-line mode, unified templates will be formed that characterize each individual train situation, which changes within the framework of the organization of the train movement process and based on local conditions. 


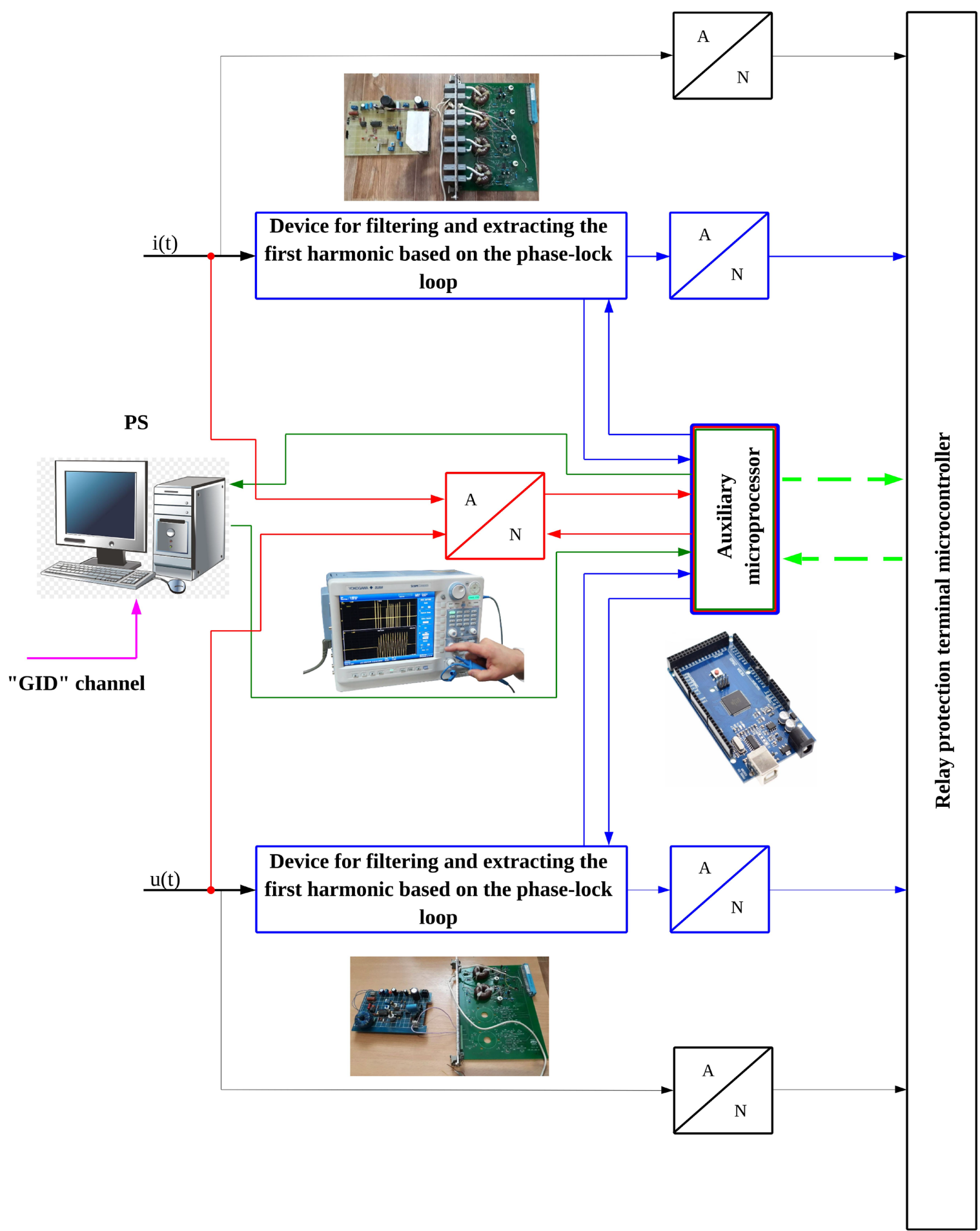

Figure 6. Schematic diagram of integration and joint operation of the proposed automated systems as part of a standard relay protection terminal DPA-27.5-TNF.

Separately, it should be noted that in this schematic solution in the form of green dash-dotted lines, a possible relationship (transmission and exchange of data) is shown, which will allow leading all information connections from the auxiliary microcontroller to the main PAU MPCM microcontroller (for exam- 
ple, in the case of full integration of the proposed automated systems directly into itself terminal when they are produced in the industrial-scale volume at the manufacturing plant).

\section{Conclusions}

For the first time, the authors obtained a unique opportunity to create a base of unified templates for electrical and train parameters, with the help of which it is possible to form presets for adjusting the operation of microprocessor relay protection for each individual train situation in online mode, using the proposed automated systems for this, and the access to the automated system of maintaining and analyzing the "GID" train sheet of the Ural-VNIIZhT, already available on the PC of the duty personnel.

In turn, the database created and operating in this way will also be an automated system that not only "trains itself" (constantly accumulating and comparing unique templates corresponding to only one train situation), but also introduces "trainability" elements into the standard algorithm of operation of the microprocessor-based relay protections of the DPA-27.5-OSF (TNF) brand currently operating on the $\mathrm{AC}$ railway network, moving away from the rigid "coarse" manually set boundaries of the monitored electrical parameters of the corresponding presets.

Most significantly, the necessity should arise to make revisions, repair or other operations for which it is required to physically disconnect a separate removable circuit panel (containing the proposed automated systems); the operation of the microprocessor relay protection will not be interrupted or disrupted in any way but will continue as usual.

\section{Confirmation}

The research was carried out with the financial support of the Trans-Baikal Institute of Railway Transport (ZABIZhT IrGUPS):

- Grant No. 76-gr of February 24, 2020 "Creation and examination of a utility model of a trainable microprocessor device for distance protection of overhead system feeders";

- Grant No. 109-gr dated April 28, 2021 "Creation and examination of a utility model of an automated microprocessor device for distance protection of overhead system feeders with trainability elements".

\section{Conflicts of Interest}

The authors declare no conflicts of interest regarding the publication of this paper.

\section{References}

[1] Epifanov, E.L. Filippov, S.A. and Vostrikov, M.A. (2017) Problems of Existing Relay Protection Devices for Catenary Feeders and Ways to Solve Them. In: Epifanov, 
E.L., Filippov, S.A. and Vostrikov, M.V., Eds., 115 Years of Railway Education in Transbaikalia: Education-Science-Production: Materials of the All-Russian Scientific and Practical Conference, Zabaikalsky Institute of Railway Transport-branch of the Federal State Budgetary Educational Institution of Higher Professional Education, Irkutsk University of Railways, Chita, 217-223.

[2] Vostrikov, M.V., Menaker, K.V. and Ushakov, V.A. (2019) Creation of a Learning Microprocessor System for Protection of Contact Network Feeders Using Adaptive Parametric Identification Methods. IOP Conference Series. Materials Science and Engineering, 760, Article ID: 012066. https://doi.org/10.1088/1757-899X/760/1/012066

[3] Guide "Ural-Vniizht": Automated System for Maintaining and Analyzing the Schedule of the Executed Movement. http://gidural.ru/doku.php

[4] Philippova, E. (2012) Reliability of Microprocessor-Based Relay Protection Devices. In: Philippova, E., Ed., Progress through Innovative Technologies-2012, Russian Federation Ministry of Education and Science Novosibirsk State Technical University, Novosibirsk, 77-78.

[5] Akhmedova, O, Soshinov, A., Bakhtiarov K., et al. (2019) Development of Relay Protection System Allowing Taking into Account Seasonality When Determining Operation Setpoints. IOP Conference Series. Materials Science and Engineering, 643, Article ID: 012125. https://doi.org/10.1088/1757-899X/643/1/012125

[6] Dikarev, P.V., Shilin, A. and Ahmedova O.O. (2019) Intelligent System Current Protection from Short Circuits. 2019 International Conference on Industrial Engineering, Applications and Manufacturing (ICIEAM), Sochi, 25-29 March 2019, 1-5. https://doi.org/10.1109/ICIEAM.2019.8742959

[7] Plakhtiev, A., Denmukhammadiev, A. and Gaziev, G. (2020) Information Universal Non-Contact Transducers of Control and Management Systems. IOP Conference Series: Materials Science and Engineering, 869, Article ID: 022034. https://doi.org/10.1088/1757-899X/869/2/022034

[8] Evdakov, A.E., Kutumov, A.E., Shadrikova, T.Y. and Shuin V.A. (2020) A Research of Digital Directional Current Protection Devices Operation Stability in Transient Modes during Single Phase to Earth Faults in 6-10 KV Networks with Isolated Neutral Point. 2020 3rd International Youth Scientific and Technical Conference Relay Protection and Automation (RPA), Moscow, 22-23 October 2020, 1-16.

[9] Piskunov, S. A. and Mokeev, V.A. (2021) Power Transformer Relay Protection with Its Condition Monitoring Function. 2021 3rd International Youth Conference on Radio Electronics, Electrical and Power Engineering (REEPE), Moscow, 11-13 March 2021, 1-5. https://doi.org/10.1109/REEPE51337.2021.9387976

[10] Ententeev, A., Usachev, S., Rybin S., et al. (2019) Developing an Analog and Discrete Signal Input Device for Applying New Detuning Algorithms. 2019 2nd International Youth Scientific and Technical Conference on Relay Protection and Automation (RPA), Moscow, 24-25 October 2019, 1-9.

https://doi.org/10.1109/RPA47751.2019.8958267

[11] Lizunov, I. N., Misbakhov, R. S., Mustafm, R. G., et al. (2016) Analysis of Methods for Determining Frequency of the Main Harmonic in the Centralized Systems of Relay Protection and Automation. Journal of Engineering and Applied Sciences, 6, 1257-1262.

[12] Xu, C.C. (2017) Design Concept of an Automated Irrigation System for Simulating Saltwater Intrusion in a Mesocosm Experiment. Engineering, 9, 563-574.

https://doi.org/10.4236/eng.2017.96035 
[13] Zhang, X., Kang, X., Ma, Y., Wang, H. and Huang, Q. (2017) The Influence of Abnormal Data on Relay Protection. Energy and Power Engineering, 9, 95-101. https://doi.org/10.4236/epe.2017.94B012

[14] Operating Manual AB036-00-000-00RE (2009) Digital Protection and Automation. Device for a $2 \times 25 \mathrm{kV}$ Traction Network Feeder TsZA-27.5-FTS/NIIEFA-ENERGO, p. 61.

[15] Hantek (2016) Hantek 6000BC/BD/6074BE V1.0.0 User's Guide. Hantek Electronic Co., Ltd.

[16] Afonskiy, A.A. and Sukhanov, E.V. (2010) Interpolation in Digital Oscillography. Instrumentation and Systems, 5, 13-46.

[17] Kiryanov, D.V. (2006) Mathcad 13. BHV-SPb, Saint Petersburg.

[18] Vostrikov, M.V., Menaker, K.V. and Pultyakov A.V. (2021) Prediction of the Dynamics of Starting and Transient Currents in Order to Increase the Selectivity of Microprocessor-Based Relay Protection Devices for Overhead Line Feeders. Transport of the Urals, 1, 86-92. https://doi.org/10.20291/1815-9400-2021-1-86-92

[19] Menaker K.V. (2019) The Device for Filtering and Isolating the First Harmonic in Microprocessor Relay Protection Devices of Contact Network Feeders Based on PLL Schemes. Patent RF, No. 2708684 C1. 